\title{
Relational Job Crafting Exploring the Role of Employee Motives with a Weekly Diary Study
}

(Accepted for Publication at Human Relations)

Yasin Rofcanin (corresponding author)

Reader of Organizational Behavior and Human Resource Management

University of Bath, School of Management

E-Mail: y.rofcanin@ bath.ac.uk

Arnold B. Bakker

Professor of Work and Organizational Psychology, Erasmus University Rotterdam

E-Mail: bakker@fsw.eur.nl

Aykut Berber*

Professor of Management

Istanbul University, School of Business

E-mail: berber@istanbul.edu.tr

Ismail Gölgeci*

Lecturer in Marketing

Norwich Business School

University of East Anglia

E-Mail: I.Golgeci@uea.ac.uk

Mireia Las Heras*

Associate Professor of Organizational Behavior and Human Resource Management IESE Business School

Barcelona, Spain

E-Mail: lasheras@iese.edu

*The last three authors contributed equally to this manuscript. 


\section{Relational job crafting: Exploring the role of employee motives with a weekly diary study}

\section{Abstract}

In this weekly diary study, we integrated research on job crafting to explore the associations between expansion and contraction oriented relational job crafting (RJC), work engagement and manager-rated employee behaviors (work performance and voice). Furthermore, we investigated cross level moderations of prosocial and impression management motives on our proposed associations. We tested our hypotheses with matched data collected over seven weeks in Istanbul, Turkey. The results from multilevel analyses revealed that a) expansion oriented RJC is positively related with work performance and voice via work engagement while b) contraction oriented RJC is negatively related with work performance and voice via work engagement, all measured at the week level. Furthermore, impression management motives of employees moderated the association between expansion oriented RJC and work engagement in that this positive association is stronger for employees low on impression management motives. Our results contribute to job crafting research in two ways. First, it focuses on RJC and discusses how and why the two opposite types of RJC (expansion versus contraction oriented) impact on work engagement and employees' key outcomes in the way they do. This addresses the question "is there a dark side to job crafting?" Second, it focuses on the importance of context and integrates two motives relevant to understand how RJC unfolds, thereby taking a step to address questions for whom (i.e., what kinds of employees), RJC is more effective and translates into enhanced (vs deteriorated) work outcomes. Moreover, our use of a weekly within-person design adds to a recently growing research stream emphasizing the dynamic nature of job crafting.

Key Words: Relational job crafting, work engagement, impression management motives, prosocial motives, performance. 


\section{Introduction}

The world of work is shaped predominantly by interpersonal interactions, connections and relationships (Grant and Parker, 2009). Dealing with others (Grant, 2007), receiving feedback (Morgeson and Campion, 2003), and forming networks and friendships are some examples that have become pervasive and crucial in today's work contexts (Latham and Pinder, 2005). In line with these trends, researchers have emphasized relational job designs (Parker et al., 2010), and particularly relational job crafting (RJC) (Laurence, 2010), as self-initiated behaviours through which employees may modify their social environment and expand or contract their interactions to complete their work effectively (Bruning and Campion, 2017). Despite the acknowledgment that job crafting does not occur in a vacuum, the relational aspects of job crafting have been overlooked in research to date (Rudolph et al., 2017; Wang et al., 2016). To emphasize that employees may modify their social environments via either expanding or contracting their relational networks at work and to contribute to the surge in research on relational job designs (Grant and Parker, 2009), we focused on RJC. Accordingly, the main aim of this research is to explore the mechanisms and boundary conditions through which expansion and contraction oriented RJC (Laurence, 2010) unfold and influence two employee outcomes: work performance and voice. We introduce work engagement as a mechanism and employees' motives (prosocial and impression management motives) as boundary conditions to study our research goals.

$\mathrm{RJC}$ is a form of job crafting behaviour that refers to exercising discretion over whom one interacts with while doing the job (Wrzesniewski and Dutton, 2001). RJC can be carried as a way of expanding (i.e., expansion oriented RCJ) as well as contracting (i.e., contraction oriented RJC) the type, number and meaning of interactions employees have with co-workers at work. Examples of expansion oriented RJC may include a focal employee expanding conversations and carrying out meetings with new colleagues from another division to achieve work targets or involve new colleagues in a project. Examples of contraction oriented RJC may 
include a focal employee limiting meetings with a co-worker regarding a project or reducing the conference calls with colleagues who may not be directly involved in the concerned project.

Research on job crafting has underlined that RJC need not and might not always have positive outcomes for the organization or employees (Lyons, 2006; Lu et al., 2014). However, the implied distinctive mechanisms and consequences of expansion oriented and contraction oriented RJC have not been explored (Van den Broeck et al., 2008). In integrating the two types of RJC, this study addresses the question "is there a dark side to RJC". It contributes to research on job crafting by discussing whether and how employees may increase or reduce the extent of communication complexity of their relational work environment, which may positively as well as negatively impact on their work engagement and work outcomes (Laurence, 2010; Rudolph et al., 2017). Our focus on the two types of RJC also contributes to recent research that has started conceptualising avoidance oriented job crafting (e.g., withdrawal job crafting which is similar to contraction oriented RJC) and demonstrating the negative consequences for employees' work outcomes that concern the employee (i.e., work performance) and the organisation (i.e., organisational commitment; Bruning and Campion, 2017). As employees' work outcomes, we focus on manager-rated work performance and voice to explore whether the consequences of job crafting concern not only the focal employee (Wang et al., 2016) by driving his/her work performance, but also the organisation by encouraging focal employee come up with constructive suggestions and discretionary change oriented ideas (LePine and Van Dyne, 1998; Ng and Feldman, 2013).

A second unexplored area in job crafting research relates to the types of employees who are more or less likely to engage in and translate the impact of job crafting, and in the context of our study, expansion and contraction oriented RJC, on work outcomes. Both expansion and contraction RJC occur at the person level (Lu et al., 2014). We, therefore, integrate employees' prosocial and impression management motives to explore what characteristics of employee tie 
to and explain for whom RJC translates into enhanced work engagement with ensuing influence on their work performance and voice. To bring a motivation angle and relate it to RCJ which entails interactions with and focus on co-workers, we delineated the role of prosocial and impression management motives as boundary conditions: The former relates to employees' tendencies to care for the needs and well-being of co-workers (Grant, 2007) while the latter refers to employees' tendencies to create a favourable image in the eyes of co-workers (Rioux and Penner, 2001). Adopting a motivation angle to understand the consequences of RJC is important because RJC is a risky endeavour, may deplete (or enrich) employees' personal resources at work, may spark negative reactions among co-workers (Demerouti et al., 2015b) and thus requires sustained energy (Rudolph et al., 2017; Wang et al., 2016).

To explore our research questions, we adopted a within-person, manager-rated weekly diary design, which constitutes a strength of this research. Theoretical and empirical work on job crafting is mostly dominated by the trait approach, exploring between-person differences in relation to the role of job crafting in employees' outcomes (Rudolph et al., 2017). Theoretically, job crafting tends to be viewed as static, one-off changes that employees introduce to their jobs (Laurance, 2010; Wrzesniewski and Dutton, 2001). Empirical research has examined relatively static perceptions of job crafting as a stable variable differentiating one individual from another (e.g., Bakker et al., 2016; Lu et al., 2014). However, recent research on job crafting suggests that employee job crafting and related employee work outcomes are dynamic, may fluctuate over weeks since the factors that determine them also vary from week to week (Petrou et al., 2017). In the context of our research, employees are likely to engage in RJC that occur less frequently than the days of a week (e.g., Petrou et al., 2017; Bakker and Sanz Vergel, 2013). For these reasons; we tested our hypotheses using a weekly-diary design (Bolger and Laurenceau, 2013) and with multi-source data collected from focal employees and their direct managers. By adopting a weekly diary design, we examine RJC in its organizational context at 
the time and level it is manifested, underlying its dynamic nature (Wang et al., 2016). We, therefore, extend most recent weekly within-person studies that started exploring the social side of job crafting with a dynamic approach (i.e., increasing social resources; Petrou et al., 2017; Petrou and Demerouti, 2015). Our conceptual model is depicted in Figure 1.

\section{--Insert Figure 1 around here--}

\section{Theory and hypothesis development}

\section{Relational job crafting}

Job crafting refers to the informal and proactive changes employees introduce to their jobs to align their jobs with their own work preferences, motives, and passions (Tims et al., 2012; Wrzesniewski and Dutton, 2001). Research has shown that employees may engage in various job crafting strategies including physical (i.e., making adjustments to the number and form of activities one does on the job), cognitive (i.e., cognitively making changes to how one sees his/her job) and relational job crafting (i.e., modifying the number and extent of interaction one has with others at work; Wrzesniewski and Dutton, 2001).

In this research, we focused on RCJ mainly for two reasons. The first reason relates to the radical shifts in the way work is constructed and conducted nowadays (Grant and Parker, 2009). Jobs and tasks are embedded in interpersonal relationships, connections and interactions. These relational perspectives have been triggered by changes in the social context of work. Internal relationships are more predominant and vital than in the past. Most organisations use teams so that employees complete their tasks interdependently; collaborating and coordinating with individuals and teams from different departments and fields (Griffin et al., 2007). Frequent technological (e.g., automation of systems) and structural changes (e.g., mergers and acquisitions) render interpersonal skills crucial for employees as their distinctively human attributes (Grant and Parker, 2009). In line with these trends, we focused on RCJ to emphasize the social characteristics of jobs and to explore social mechanisms through which RJC may influence employees' behaviours and attitudes. 
The second reason relates to the overlooked role of RJC in the context of broader job crafting research. Despite being an individual proactive process, job crafting has social aspects and does not occur in a social vacuum (Laurence, 2010). One specific type of job crafting that particularly entails interpersonal elements is RJC (Lu et al., 2014; Wrzesniewski and Dutton, 2001). Employees may either expand or limit the nature, number and types of interpersonal interactions and communications they have with their co-workers at work. The former is marked by a self-initiated process of expanding one's relational networks at work ( $\mathrm{Lu}$ et al., 2014; Van den Broeck et al., 2008). In contrast, contraction oriented RJC is marked by employees' efforts to reduce the extent of interaction with others at work. This could happen for various reasons, for example, to simplify a job and ensure one has sufficient resources to devote to work-related goals or has less extent of communication complexity at work (Laurence et al., 2010) or to preserve resources or time for work by reducing time spent with colleagues with whom the employee does not get along well (Niessen et al., 2016). Taking into account the tenet that employees may both expand and contract their relational networks at work and to contribute to this nascent yet significant field of job crafting research (Rudolph et al., 2017), we focused on expansion and contraction oriented RJC in this study.

\section{Relational job crafting and work outcomes: The mediating role of work engagement}

We argue that expansion oriented RJC is positively associated with work performance (in-role performance) and voice (extra-role performance) while contraction oriented RJC is negatively associated with these work outcomes via work engagement. Work engagement is defined as a positive, fulfilling, work-related state of mind that is characterized by vigor, dedication, and absorption (Schaufeli and Bakker, 2004). In their work on the "drivers of work engagement”, Bakker et al.’s (2011) propose that job resources relate to work engagement due to their intrinsic and extrinsic motivational roles. From this perspective, expansion oriented RJC is expected to play an intrinsic motivational role by satisfying one's need for belongingness 
(e.g., Halbesleben, 2010; Van den Broeck et al., 2008), as it concerns with enlarging workrelated networks or dealing with new people to complete work effectively (Laurence, 2010). On the contrary, contraction oriented RJC, which aims to shirk one's relationships and networks at work, does not address and contribute to one's need for belongingness (Laurence, 2010).

These relational resources, which we view as targets of RJC, are also expected to play an extrinsic motivational role in driving (vs reducing) work engagement. Expanding relational networks at work creates a resourceful work environment that facilitates goal achievement and task completion (Bakker et al., 2012). This means that expansion oriented RJC enhances one's abilities and helps meet one's work-related goals (Van den Broeck et al., 2008). Contracting one's relational network, on the other hand, prevents the creation of resourceful work and supportive work environment by inhibiting collaboration with co-workers to complete work effectively. This suggests that a focal employee does not create the opportunity to benefit from managers and co-workers (e.g., feedback, support, learning new ways of working from colleagues), negatively influencing one's state of work engagement. Indeed, contraction oriented RJC may represent a way of making sure that one has sufficient resources to devote to non-work related purposes (Lu et al., 2014).

In support of the motivating role expansion and contraction oriented RJC have, in their weekly-diary study, Petrou et al. (2017) revealed that increasing social resources, due to its role of providing employees with access to emotional and instrumental resources, was positively associated with work engagement (e.g., intrinsic motivational role). Tims et al. (2013; 2012) showed that engaging in job crafting (e.g., increasing social resources) led to increases in social resources, further supporting the role of job crafting in creating resources. Petrou et al. (2012) revealed that increasing social resources dimension of job crafting creates learning and development opportunities, promoting and encouraging self-growth and development opportunities (e.g., extrinsic motivational role). In the light of this discussion and previous 
evidence, we posit a positive link between expansion oriented RCJ and work engagement and a negative link between contraction oriented RJC and work engagement.

In turn, engaged employees who have expanded their relational networks, are likely to have abundant resources to perform their duties (work performance; Borman and Motowidlo, 1997). In experiencing positive feelings like enthusiasm and eagerness, engaged employees build a range of physical, social and intellectual resources which help them perform better at work (Bakker and Xanthopoulou, 2009; Luthans and Youssef, 2007). These engaged employees who have expanded their relational networks are also likely to engage in voice which refers to active and constructive endeavours to improve organizational functioning (Chan, 2014), and which concentrates on changing the status quo (Raub and Robert, 2010). Experiencing positive emotions that are high in arousal and activation (Bakker and Bal, 2010) widen these employees' thought-action repertoires and encourage them to go the extra mile for their organization (Demerouti et al., 2015). Experiencing positive emotions also increases employees' willingness to expend discretionary efforts on helping their organization, because engaged employees are likely to have a broader conception of their role and go beyond the requirements of their job to contribute to the organization and its people (Rich et al., 2010).

On the contrary, employees that lack a state of work engagement due to shirking their relational networks at work, are not likely to be equipped with resources necessary to perform their required tasks (i.e., social, cognitive and physical resources necessary to complete one's task effectively; Halbesleben, 2010). Not feeling engaged with their work as a result of contracting their relational networks at work, these employees can experience negative emotions that are high in arousal and activation (Bakker and Bal, 2010), discouraging them from engaging in extra-role behaviors. Indeed, an important aim of contraction oriented RJC is to have a simplified and a narrower perception of one's work, which usually does not entail 
extra role duties and requirement to contribute to one's work and people in the organization (Lu et al., 2014; Laurence, 2010).

Indirectly supporting our argument, a recent meta-analysis (Marinova et al., 2015) reveals that work engagement is an important predictor of change-oriented behaviors (conceptualized as change-oriented proactive behaviors), underlining its mediating role and explaining how and why enriched job characteristics predict change-oriented behaviors. Grant and Parker (2009), in their review on relational job design, underline the role of work engagement as a mechanism to translate the impact of social aspects of job design into work outcomes. Drawing on this research stream and building on the few empirical studies that have demonstrated a positive association between work engagement and similar constructs such as contextual work performance (e.g., Demerouti et al., 2015), we set our first hypothesis as:

Hypothesis 1(a): Expansion oriented RJC is positively associated with work performance and voice via work engagement, all measured at the week level. Hypothesis 1(b): Contraction oriented RJC is negatively associated with work performance and voice via work engagement, all measured at the week level.

Cross-level moderation of prosocial and impression management motives on the associations between RJC and work engagement

Motives pertaining to one's interactions with others can condition the influence of RJC on work engagement. Accordingly, we include two types of employee motives (i.e., prosocial and impression management motives) to arrive a more nuanced understanding of the association between the two types of RJC and work engagement. Prosocial motives refer to a desire to promote the well-being of co-workers (Grant and Berg, 2011). We argue that for 
employees higher on prosocial motives, the positive association between expansion oriented RJC and work engagement strengthens.

Expansion oriented RJC involves efforts to build social capital and networks to improve one's goal achievement at work (Laurence, 2010). Prosocially motivated employees care for their co-workers and help them, with the ultimate intention of contributing to their organization (Grant, 2008). These employees are more likely to make use of and translate the impact of expansion oriented RJC into the state of enhancing work engagement because for them, engaging with new colleagues and developing relational networks are instrumental means to achieve their work goals (Sheldon and Houser-Marko, 2001). To illustrate, imagine a prosocially motivated employee: For this employee, developing friendships with others at work or dealing with new people are instrumental means to contribute to the needs of co-workers, learn about new developments, or acquire new skills to perform effectively (Rofcanin et al., 2018). In other words, when employees high in prosocial motives expand relational aspects of their jobs (e.g., establish new relationships), they are likely to feel energized, because in such contexts they can reflect their true selves and nurture their relationships with co-workers by offering help and learning new things from them. In creating a resourceful work environment characterized by mutually beneficial work relationships, such employees are likely to feel intrinsically motivated and energized to do their jobs, experiencing enhanced work engagement (Bakker, 2011). Consequently, this employee is likely to feel positive, focused and dedicated to his/her job, leading to an enhanced state of work engagement.

On the contrary, for prosocially motivated employees (i.e., high on prosocial motives), we propose that the negative association between contraction oriented RJC and work engagement is amplified. An ultimate purpose and meaning of work for prosocially motivated employees is to contribute to the functioning of organization via helping others (Grant and Bolino, 2016). However; by engaging in contraction oriented RJC, they limit the extent to 
which they deal with new people and address their needs as well as concerns. To illustrate, imagine a situation where a prosocially motivated employee cuts down his/her communication with colleagues and clients to work on a task. This situation limits the options prosocially motivated employee might have to learn what co-workers need, their problems concerning work or other issues (e.g., new task, skill and developmental opportunities at work), all of which lead the focal employee feel less positive, focused and dedicated to his/her job. This is because, for a prosocially motivated employee, the meaning of work emanates from interactions with others (Grant, 2008). We thus expect prosocially motivated employees to be less engaged in their work when they practice contraction oriented RJC. Our second hypothesis is:

Hypothesis 2: Trait prosocial motives moderate the association RJC and work engagement: The positive association between expansion oriented RJC is stronger for prosocially motivated employees $(\mathrm{H} 2 \mathrm{a})$; the negative association between contraction oriented RJC and work engagement is stronger for prosocially motivated employees $(H 2 b)$.

Impression management motives refer to employees' efforts to present a favourable image to others (Bolino and Klotz, 2015). Pretending to be busy, avoiding interactions with colleagues and prioritizing extrinsic rewards such as promotions characterize employee behaviours driven by impression management motives (Bowler and Brass, 2006; Grant and Mayer, 2009). We argue that impression management motives moderate the associations expansion and contraction oriented RJC have with work engagement.

Employees acting on impression management motives are likely to show that they look hard-working, successful and deserve a promotion (Grant and Mayer, 2009). These motives conceal their real sense of self, leading to incongruence between what is felt and reflected (Grant and Bolino, 2016). Guided by this logic, when employees high in impression management motives expand their relational networks at work (e.g., establish new 
relationships, or deal with new clients and colleagues), they are likely to feel less engaged because such behaviors do not reflect their true selves and deplete from their personal resources. These employees tend to put extra effort into projecting and sustaining an image of a caring coworker, depleting personal resources such as energy and self-efficacy. Previous research has demonstrated that personal resources such as optimism and self-efficacy are crucial to one's work engagement (e.g., Xanthopoulou et al., 2012) and lack of such resources impacts on work engagement negatively (Goldberg and Grandey, 2007). Thus, in a context in which forming new relationships is not characterized by genuine intentions and meaningful interactions, a focal employee high in impression management motives is less likely to feel engaged. We thus expect the positive association between expansion oriented RJC and work engagement to be weaker for employees high on impression management motives.

As outlined previously, contraction oriented RJC involves efforts to minimize contact and interaction with others at work, with the ultimate goal of projecting a simplified version of their work and have more resources devoted to non-work domains (Laurence, 2010). Thus, when employees, high on impression management motives, contract their relational resources, they are likely to feel less disengaged because such behaviours align with their true intentions and goals at work (Goldberg and Grandey, 2007). Contraction oriented RJC provides them with more personal resources, which otherwise would be depleted by engaging in expansion oriented RJC (Grant and Bolino, 2016). We thus expect employees' impression management motives to attenuate the negative association between contraction oriented RJC and work engagement. The third hypothesis is as follows:

Hypothesis 3: Trait impression management motives moderate the association RJC and work engagement: The positive association between expansion oriented RJC and work engagement is weaker for employees driven with impression management motives $(\mathrm{H} 3 \mathrm{a})$; the negative association between contraction oriented RJC and 
work engagement is weaker (i.e., attenuated) for employees driven with impression management motives $(H 3 b)$.

\section{Method}

\section{Procedure and sample}

We used a multilevel, multi-source weekly diary design (over seven weeks) to test our hypotheses (Bolger and Laurenceau, 2013). Our sample consisted of full-time employees who were enrolled in an Executive MBA program. Before the study commenced, all potential participants enrolled in this module $(\mathrm{N}=123)$ were informed of the study goals. They were assured that participation in the study was neither associated with their academic achievements at school nor a course requirement. In the end, 67 students decided to participate voluntarily every week over a period of seven weeks. Due to missing data, we utilized surveys of 43 employees (64\% of participation).

Prior to the start of the study, the participants completed a trait survey that included measurements of demographics, control variables and trait motives. One week following the initial week, we started to collect weekly-level data. Participants were asked to complete their weekly surveys on Mondays for the previous week (Monday to Friday) and were asked to provide their managers with a sealed envelope containing a copy of our managers' survey form. The managers evaluated the work performance and constructive voice behaviors of their subordinates and were asked to re-seal their envelopes and return them to their subordinates. The following week, each focal employee returned two surveys to the first author of the study. They provided the names of the managers who had filled in the surveys for them, and the data were matched using the managers' and focal employees' names. To ensure that it was the supervisors who filled out the surveys on behalf of their subordinates, we randomly e-mailed and called the supervisors using publicly available contact information. Owing to missing data, our final sample consisted of 43 subordinates $(\mathrm{N}=43 ; 301$ data points $)$. We translated our survey into Turkish using the suggested procedures (Prieto, 1992). 
We carried out power analysis (Ellis, 2010) to determine and ascertain the sample size at Level 2. The findings (procedure and detailed results can be obtained from the first author upon request), with the target of achieving a 95\% confidence interval supported our Level $2 \mathrm{~N}$. Moreover, our sample was in line with studies that suggest a minimum level for achieving meaningful and significant effect sizes (Scherbaum and Ferreter, 2009; Maas and Hox, 2004). Finally, we compared our Level 2 sample size with related within-person research. While there are studies that used Level 2 sample size which is below 42 (e.g., 30; To, Fisher, Ashkanasy, \& Rowe, 2012) there are also studies that use Level 2 sample size that is above 42 (e.g., Breevaart et al., 2016).

As one of few executive MBA classes taught in English, this program has demanding admissions requirements regarding academic achievement and previous experience. On graduation, the students' career development and promotions are tracked. This was, therefore, an appropriate sample through which to observe job-crafting behaviors. The average age of participants was 31.60 years $(\mathrm{SD}=6.03$ years), and 44 percent were male. On average, they had worked with their current company for 3.23 years $(\mathrm{SD}=1.64$ years).

Our participants worked in managerial-level positions across a range of industries: 44 percent worked in financial services, 28 percent in manufacturing and 18 percent in consultancy, while nine percent reported themselves as working in an 'other' category (including self-initiated businesses, higher education and the hotel industry). Within their companies, 18 percent worked in finance, 18 percent in sales, 18 percent in business development, 16 percent in marketing and 28 percent in client relations management. 
Measures. For all the questions, we used a five-point Likert scale. For the weekly questionnaire, the participants were asked to answer questions relating to the past week.

\section{Weekly measures}

Relational job crafting. Subordinates assessed expansion (4 items) and contraction (4 items) oriented RJC using the scale developed by Laurence (2010). Because the original scale is unpublished, we were careful to select items that had satisfactory exploratory factor analysis (EFA) loading values in the original study (above 0.60). In our study, the EFA results revealed that expansion and contraction oriented RJC items had satisfactory factor loadings (all above 0.60 across seven weeks; full results and items available from the first author). Moreover, the items for the RJC measure had been used in previous research, supporting the validity of our items (Lu et al., 2014). One example for expansion oriented RJC is: "Last week, I increased the amount of communication I have with others to get my job done effectively at work" $(\alpha=0.85)$. One example for contraction oriented RJC is "Last week, I limited my relational network to effectively achieve my work goals" $(\alpha=0.93)$. Please refer to the Appendix for the items.

Work engagement. Subordinates evaluated work engagement using the Utrecht Work Engagement Scale (UWES; Schaufeli et al., 2006). This scale consists of three dimensions with three items for each (i.e. vigor, dedication, absorption). Example items included: "Last week, I felt bursting with energy" (vigor); "Last week, I was enthusiastic about my work" (dedication); and "Last week, I was immersed in my work" (absorption; ranging from $1=$ never to $5=$ always). We combined all three dimensions to produce an aggregate score for work engagement $(\alpha=0.87)$.

Work performance. Managers evaluated the work performance of their subordinates on a three-item scale used by Gilboa et al. (2008). One example was "Last week, the performance of this employee was better than the work performance of most of his/her co-workers" (ranging from $1=$ strongly disagree to $5=$ strongly agree; $\alpha=0.78$ ). 
Voice. Managers evaluated employees' voice behaviors using four items from LePine and Van Dyne's (1998) scale. One example was "Last week, this employee communicated his/her opinions about work issues to others in this group even if his/her opinion is different and others in the group disagree with him/her" (ranging from $1=$ never to $5=$ always; $\alpha=0.81$ ).

\section{Trait-level measures}

Prosocial motives. Subordinates assessed subordinates' trait-level prosocial motivation using Grant's (2008) four-item scale, which evaluates the extent to which focal employees are motivated to help others at work. An example item was 'I want to help others through my work' (ranging from $1=$ strongly disagree to $5=$ strongly agree; $\alpha=0.92$ ).

Impression management motives. Subordinates evaluated their impression management motives directed at their co-workers and supervisors with a scale developed by Rioux and Penner (2001). We used the four items from the eleven items of this scale emphasizing imagebuilding efforts toward colleagues. We selected the items with the highest loading values in the original study (Rioux and Penner, 2001). An example item was 'I want to avoid looking bad in front of my co-workers' (ranging from $1=$ strongly disagree to $5=$ strongly agree; $\alpha=0.94$ ).

\section{Controls}

Controlling for subordinates' and managers' age, gender, role in the company and team size did not change the overall results. Hence, they were excluded from further analysis.

Time. Variability in an outcome variable may be due either to variability in the predictor variable or other theoretically relevant variables or simply to the passage of time (Bolger and Laurenceceau, 2013). Diary studies may account for the confounding effects of time by using a time index as a covariate in estimated models, strengthening the assumption of putative causality investigated between constructs marked by high fluctuations in these constructs over time. Accordingly, in line with the suggestions of previous research (Madrid et al., 2014), to control for time-serial dependence, we used week as a time index. 
Lagged Effects of Outcomes. To strengthen the causality, in line with suggestions (Bolger and Laurenceceau, 2013), we controlled for the lagged effects of our outcome variables (e.g., when predicting the impact of relational job crafting on work engagement, the lagged effects of work engagement were controlled for).

\section{Analytical strategy}

Owing to the nested structure of our data (weeks nested in persons), we applied multilevel analyses using MLwiN software to test our proposed hypotheses (Rasbash et al., 2000). To determine whether multilevel analysis was appropriate, we calculated the intra-class correlation statistics ICC(1)s for our level 1 (weekly variables): expansion oriented RJC (35\%), contraction oriented RJC (37\%), work engagement (30\%), work performance (39\%) and voice $(38 \%)$. The results supported the use of multilevel analysis.

We used the Monte Carlo method for assessing mediation (MCMAM) to test our indirect effects. This method uses simulations with 20,000 iterations and relies on a productof-coefficients (ab) approach (MacKinnon \& Fairchild, 2009). The advantage of this method is that it draws randomly from the joint distributions of the parameter estimates, calculates the product value of the two parameter estimates and repeats this very many times. In the end, a confidence interval is estimated to test indirect effects (Bauer et al., 2006). When the confidence intervals do not contain zero, it means an indirect effect is established. We used an online tool developed by Selig and Preacher (2008) to calculate confidence intervals, and tested our moderation hypotheses following recommended procedures (Aiken and West, 1991). We used the procedures outlined by Edwards and Lambert (2007) to test the first-stage moderated mediation. This method integrates the moderation and mediation into a single model, and explores whether the indirect effect is significantly different at low and high conditions of the value of the moderator variable. We centred the control variables and trait-level work motives 
on the grand mean, and the weekly measures on their respective person means (Ohly et al., 2010).

\section{Results}

Table 1 shows the means, standard deviations and correlations for all the study variables.

\section{--Insert Table 1 around here--}

Before testing our hypotheses, we ran multilevel confirmatory factor analysis (CFA) to explore the factorial structures of our measures using M-PLUS. The measurement model distinguishing between the seven study variables of the proposed model showed a satisfactory fit with the data $(\chi 2=728.790 ; \mathrm{df}=261, \chi 2 / \mathrm{df}=2.79, p<0.001 ; \mathrm{CFI}=0.82 ; \mathrm{TLI}=0.80$; RMSEA $=0.08 ;$ SRMR within $=0.07 ;$ SRMR between $=0.06$ ). We compared our measurement model to alternative models. In Alternative Model 1, we combined expansion and contraction oriented RJC into one factor ( 6 constructs: $\chi 2=1015.462 ; \mathrm{df}=265, \chi 2 / \mathrm{df}=2.79, p<0.001$; $\mathrm{CFI}=0.71 ; \mathrm{TLI}=0.67 ; \mathrm{RMSEA}=0.10 ; \mathrm{SRMR}$ within=0.09; $\mathrm{SRMR}$ between=0.06). In Alternative Model 2, we combined work performance and voice into one factor; 6 constructs: $\chi^{2}=1015.462 ; \mathrm{df}=265, \chi 2 / \mathrm{df}=2.79, p<0.001 ; \mathrm{CFI}=0.71 ; \mathrm{TLI}=0.67 ; \mathrm{RMSEA}=0.10$ SRMR within= 0.09; SRMR between=0.06). The results demonstrated that our measurement model had better fit than alternative models, supporting the discriminant validity.

Hypothesis 1(a) proposed that expansion oriented RJC would be positively related to work performance and voice via work engagement, all measured at a weekly level. As the confidence intervals did not include a value of zero for work performance $(95 \% \mathrm{CI}=$ $[0.04 / 0.14])$ and for voice $(95 \% \mathrm{CI}=[0.03 / 0.10)$, this hypothesis was supported (Table 2). Hypothesis 1(b) proposed that contraction oriented RJC would be negatively related to work performance and voice work engagement, all measured at the weekly level. As the confidence intervals did not include a value of zero for work performance $(95 \% \mathrm{CI}=[-4.30 /-1.82])$ and for voice (95\% CI $=[-5.11 /-3.19)$, this hypothesis was supported (Table 3). 


\section{--Insert Table 3 around here--}

Hypothesis 2(a) proposed that the positive association between expansion oriented RJC and work engagement is stronger for employees high on prosocial motives. As the interaction term was insignificant, this hypothesis was not supported $(\gamma=0.07, \mathrm{p}=1.75$; Table 4, Model 1). Hypothesis 2(b) proposed that the negative association between contraction oriented RJC and work engagement is stronger for employees high on prosocial motives. As the interaction term was insignificant, this hypothesis was not also supported $(\gamma=-0.06, \mathrm{p}=0.85$; Table 4 , Model 2).

Hypothesis 3(a) proposed that the positive association between expansion oriented RJC and work engagement is weaker for employees driven with impression management motives. The interaction term is significant, which supports the hypothesis $(\gamma=-0.11, \mathrm{p}<0.01$; Table 4 , Model 3). We plotted the interaction at one standard deviation above and below the mean of the impression management motive. For low levels of trait impression management motives, the simple slope was significantly positive (gradient of slope value $=0.41, \mathrm{t}=-2.34, \mathrm{p}<0.01$ ), for high levels of trait impression management motives, the simple slope was not significant (gradient of slope value $=-0.13, \mathrm{t}=-1.15, \mathrm{p}=0.25)$. Hypothesis $3(\mathrm{~b})$ proposed that the negative association between contraction oriented RJC and work engagement is weaker (i.e., attenuated) for employees driven with impression management motives. The interaction term was insignificant $(\gamma=0.07, p=1.75$; Table 4, Model 4), which does not support our hypothesis. See Table 4 and Figure 2 for details.

\section{--Insert Table 4 around here- \\ --Insert Figure 2 around here--}

\section{Discussion}

\section{Theoretical contributions}

The present study aimed to test the mechanism and boundary conditions through which expansion versus contraction oriented RJC impact on employees' work performance and voice 
via work engagement. Our results from matched data of subordinates and their managers collected over seven weeks revealed unique findings concerning how RJC unfolds. A key contribution of this study is that it provides evidence for the dark side of RJC. Research to date has focused on the positive side of job crafting in general (Wang et al., 2016), suggesting that employees mostly engage in expansion oriented job crafting (Demerouti et al., 2015b). In particular, research building on the JD-R theory of job crafting has consistently shown that increasing resources and challenging demands relate to work outcomes positively (Rudolph et al., 2017). However, when it comes to reducing hindering work demands, the impact on work outcomes is inconsistent and at best weak and negative (Rudolph et al., 2017). For example, the findings in the study of Demerouti et al., (2015b) showed that reducing demands on daily basis related to work engagement negatively which then reduced task performance and altruism.

Adding to this line of research, our findings showed that contracting relational resources and limiting the extent of communication with co-workers (i.e., engaging in contraction oriented RJC) deteriorated manager-rated work performance and voice via its negative influence on work engagement. Viewing contraction oriented RJC as a self-driven strategy to achieve better person-job fit, it is not surprising to see that on weeks, employees adopted this strategy, they also refrained from fulfilling their job requirements (i.e., work performance) and going the extra mile for the organization (i.e., voice, Jex, 1998). Employees who limited their social communication networks and interactions may have selected the most important tasks to invest their energy (Demerouti, 2014). However, these employees are usually less adaptive and effective in performing their daily duties and dealing with change (Demerouti et al., 2014).

Our findings concerning the influence of contraction oriented RCJ also add to recent research, which has started focusing on the dark side of job crafting: In their recent study, Bruning and Campion (2017) developed a taxonomy of approach and avoidance oriented role and resource crafting strategies. The results of this study revealed that in general approach 
oriented role and resource crafting influenced performance and commitment of employees positively. On the contrary, withdrawal crafting, which refers to the systematic removal of oneself from a person or situation, was positively related to work withdrawal and negatively related to work impact of employees. The authors underlined that one should be cautious about the withdrawal job crafting as it may have longer-term effects on one's performance and organizational commitment. Current research on job crafting suggests that the consequences of job crafting involving reduction of social resource and demands remain unclear (Demerouti et al., 2015b; Tims et al., 2012). Our findings support that both expansion and contraction oriented RJC occur in work contexts with opposite implications for work outcomes.

Another key contribution of this research is its focus on the individual characteristics, namely employees' motives, as contextual variables to address the question for whom, the impact of RCJ become more (vs less) significant. Despite its relevance, research on job crafting has not examined the role of employees' motives in explaining the boundary conditions of job crafting (Wang et al., 2016). Regarding the role of trait impression management motives, the positive association between expansion oriented RJC and work engagement became stronger for employees lower on impression management motives. Impression management motives did not influence the association between contraction oriented RJC and work engagement. To understand why the positive association between expansion oriented RJC and work engagement did not change for employees characterized by high impression management motives, one might look at the characteristics of co-workers with whom focal employees interact.

Impression management theory proposes that employees assume that supervisors will think highly of them for forming relationships with well-regarded and influential co-workers (Bowler and Brass, 2006). This is because supportive relationships with influential or star employees provide instrumental benefits, while the benefits of relationships with common peers are unclear or insignificant (Crandall et al., 2007). Moreover, relationships with peers or 
projects may not offer the same opportunities to 'bask in the glory' as those formed with star employees (Crandall et al., 2007). In support of this argument, a recent study by Long et al. (2014) shows that impression management motives are positively associated with supportive relationships only with star employees. Given that only a limited percentage of employees in an organization are stars or talents (Call et al., 2015), it is unlikely that participants in our study with strong impression management motives consider normal peers or projects when reflecting on their behaviours and attitudes (e.g., expansion oriented RJC and work engagement).

Our findings indicated that for employees high on prosocial motives, the impact of RJC (both expansion and contraction oriented RJC) on work engagement was not significant. This could be due to the resource draining and energy depleting role associated with high prosocial motives (Grant and Bolino, 2016). To date research on prosocial motives has highlighted its positive impact on individuals and organizations. Nevertheless, there are important drawbacks to prosocial motivation. As such, employees characterized by high prosocial motives are likely to sacrifice their own personal and cognitive resources, mainly time, energy and focus, to help co-workers (Grant and Bolino, 2016), thereby consuming their energy (Fineman, 2006). Recently, studies have associated high prosocial motives with the feelings of conflict, stress, role overload and citizenship fatigue (Bolino, Hsiung, Harvey, and LePine, 2015).

Indeed, high prosocial motives require a substantial investment of time and energy to care for co-workers' well-being (Bolino and Klotz, 2015) which depletes from self-regulatory resources of time, energy and attention (Lanaj et al., 2016). As a result, these employees are likely to face challenges in experiencing and utilizing the impact of RJC on their state of work engagement. Moreover, these employees are likely to feel worn out, tired and on the edge, because they care too much to promote the well-being of their co-workers, which lead them to cut back on their contributions to the organizations (i.e., work performance; Weinstein and 
Ryan, 2010). Considering this point, we suggest future research to explicitly measure whether high prosocial motives deplete one's resources.

Only recently, studies have begun to integrate the dynamic nature of job crafting behaviors and the impact they have on employee outcomes (Petrou et al., 2017). While job crafting has most often been studied at a single point in time or at different points with time lags, the underlying assumption has been that job crafting behaviours are stable over time. By studying within-person changes in RJC, further future research questions arise: how does unit climate influence fluctuations of relational - other types of job crafting behaviours - on employee outcomes? While such questions can be explored with daily or weekly designs, we looked at weekly fluctuations mainly for two reasons: Daily diary studies tend to be confounded with missing data. That is, in the context of our study, we would not expect employees to get in contact with their co-workers and increase their communication networks every single day in different contexts and for different reasons. The participants in our study typically were employed in projects in which work tasks typically differ on a weekly basis rather than a daily basis (Ohly et al., 2010). Second, we followed previous research which has shown that individuals are able to perceive and report on their work engagement (e.g., van Woerkom, Oerlemans \& Bakker, 2016), job crafting (Petrou et al., 2017) and interactions with others on a weekly basis most accurately (Breevaart et al., 2016), in contexts where working week is from Mondays to Fridays, with the weekends as natural breaks.

\section{Managerial implications}

Regarding our contributions to enhancing managerial practice, our findings revealed that while expansion oriented RJC drives employee work engagement and contribute to their functioning at work; contraction oriented RJC have detrimental effects on work engagement and functioning at work. This suggests that interventions at work should focus on finding ways and providing employees with resources to adopt an expansive strategy of job crafting. A way 
to discourage contraction oriented RJC would be to provide employees with individualised coaching, mentoring so that they feel supported and work in a resourceful context. Regarding the dynamic nature of RJC; the most frequent types of expansion oriented RJC are expanding communication with others $(87 \%)$ and dealing with new people at work $(65 \%)$. In terms of contraction oriented RJC, the most frequent types were limiting communication with others (86\%) and limiting the extent to which one deals with new people at work (64\%). Accordingly, dynamic interventions might be carried out to support expansion oriented RJC and limit contraction oriented RJC.

At the job level, creating a work environment that emphasizes ongoing social support and changing work procedures to facilitate continuous feedback and communication are among ways to encourage expansion oriented RJC (Bakker, 2014). At the person level, ongoing training, coaching and developmental support might be used to build positive social interactions at work, which is, intended to prevent employees from withdrawing and contracting their relational networks at work. For example, expansion oriented RJC training might be conducted, in which employees attend workshops on job crafting, develop their job crafting plans and keep records of their weekly crafting activities for later evaluation. Organising this kind of training with the support of HR departments and managers will enable organizations to evaluate how RJC influences the work engagement and performance outcomes of employees who receive such training (e.g., van Wingerden et al., 2017).

\section{Limitations and further research avenues}

A first limitation is that, because our study was cross-sectional, we were unable to ascertain causality, so we ran plausible models to explore whether other explanations were possible. We explored the mediating role of work engagement between employees' work outcomes and their RJC. The rationale for this argument is based on the perspective that employees who perform well and who go the extra mile for their organization may feel more 
engaged, leading them to craft their relational work environment and create more resources. None of the indirect paths was significant, as the confidence intervals included the value of zero. We also explored whether work engagement leads to employees' engaging in RJC which may then lead to enhanced work outcomes. This is built on the argument that the association between work engagement and job crafting is dynamic (Bakker, 2011). None of the indirect paths was significant (details of results can be provided upon request). Furthermore, our use of lagged effects of each outcome variable and Time Index (week) strengthens the causality of our research. Nevertheless, we suggest studies to undertake experimental designs to establish causal orders among our proposed associations (van Wingerden, Bakker, \& Derks, 2017).

Supervisors evaluated the voice behaviours of their subordinates. This may have created bias in our results because 1) voice behaviours may have been evaluated as suggestions or mere exchange ideas by supervisors; 2) subordinates, knowing that their behaviours are evaluated by supervisors, may have stayed away from expressing their genuine change oriented ideas. However, a meta-analysis by $\mathrm{Ng}$ and Feldman (2012) revealed that there are no statistically significant differences between self-versus manager-rated voice behaviours in terms of its association with its antecedents and consequences. To reduce common-method biases and provide a more objective evaluation of subordinates' outcomes, in line with recent research (Duan et al., 2017), we utilized supervisor ratings. Nevertheless, we suggest future research to replicate and extend the findings of this study by utilizing different conceptualizations of voice (e.g., promotive and prohibitive voice).

In our findings, contraction oriented RJC was negatively associated with work outcomes via work engagement. While this finding is line with previous research, which has demonstrated a negative association between contraction oriented RJC and work outcomes (organisational commitment, job satisfaction; Laurence, 2010), underlying reasons and motives to reduce the relational networks and communication at work may be different and may have a positive 
impact on work outcomes. Perhaps employees are contracting to be able to devote their energy to specific tasks or other aspects of their jobs, implying positive influence on employee creativity. Uncovering mechanisms and ways that employees contract relational elements of their jobs is an important next step in the refinement of this construct.

In our study, we built on the argument that engaging in expansion (vs contraction) oriented RJC motivates job crafters both intrinsically and extrinsically (vs for contraction RJC), leading them to feel engaged. Since RJC involves interaction with others, it could be that coworkers or managers may not be as supportive as focal employees expect, hampering the effective implementation and consequences of RJC. Future studies may tackle this aspect by integrating the role of co-worker support and measuring whether employees build emotional, instrumental and relational resources following their RJC efforts.

In this study, we focused only on RJC due to resource limitations (time and energy of participants) and study purposes. Within-person changes, mechanisms and boundary conditions of how cognitive and task crafting unfold are likely to differ (Rudolph et al., 2017) and we suggest future studies to explore these topics. This study was conducted in a setting characterized predominantly by high in-group collectivism (Kabasakal and Bodur, 2002). In such contexts, individuals are concerned about their relationships with and the reactions of others. Hence, others might see engaging in RJC as a threat in a team environment. It would be interesting to explore how different cross-cultural contexts (e.g., individualism versus collectivism) influence the consequences of relational and, if possible, other types of job crafting.

\section{References}

Aiken LS and West SG (1991) Multiple Regression: Testing and Interpreting Interactions. Newbury Park, CA: Sage.

Bakker AB (2011) An evidence-based model of work engagement. Current Directions in Psychological Science 20(4): 265-269. 
Bakker AB Albrecht SL and Leiter MP (2011) Key questions regarding work engagement. European Journal of Work and Organizational Psychology 20 4-28.

Bakker AB and Bal PM (2010) Weekly work engagement and performance: A study among starting teachers. Journal of Occupational and Organizational Psychology 83(1): 189206.

Bakker AB and Leiter MP, eds (2010) Work Engagement: A Handbook of Essential Theory and Research. New York, NY: Psychology Press.

Bakker AB Rodriguez-Muñoz A and Sanz Vergel AI (2016) Modelling job crafting behaviours: Implications for work engagement. Human Relations 69(1): 169-189.

Bakker AB Tims M and Derks D (2012) Proactive personality and performance: The role of job crafting and work engagement. Human Relations 65(10): 1359-1378.

Bakker AB and Sanz Vergel AS (2013). Weekly work engagement and flourishing: The role of hindrance and challenge demands. Journal of Vocational Behavior, 83(2): 397-409.

Bakker AB and Xanthopoulou D (2009) The crossover of daily work engagement: Test of an actor-partner interdependence model. Journal of Applied Psychology 94(6): 15621571.

Bauer DJ, Preacher KJ and Gil KM (2006) Conceptualizing and testing random indirect effects and moderated mediation in multilevel models: New procedures and recommendations. Psychological Methods 11(2): 142-163.

Bolger and Laurenceau (2013). Intensive Longitudinal Methods: An Introduction to Diary and Experience Sampling Research. New York: Guilford.

Bolino MC Hsiung HH Harvey J and LePine JA (2015) "Well, I'm tired of tryin'!" Organizational citizenship behavior and citizenship fatigue. Journal of Applied Psychology, 100(1): 56-74.

Bolino MC and Klotz AC (2015) The paradox of the unethical organizational citizen: The link between organizational citizenship behavior and unethical behavior at work. Current Opinion in Psychology, 6: 45-49.

Borman WC and Motowidlo SJ (1997) Task performance and contextual performance: The meaning for personnel selection research. Human Performance 10(2): 99-109.

Bowler WM and Brass DJ (2006) Relational correlates of interpersonal citizenship behavior: A social network perspective. Journal of Applied Psychology 91(1): 70-82.

Breevaart K, Bakker AB, Demerouti E and Derks D (2016) Who takes the lead? A multi-source diary study on leadership, work engagement, and job performance. Journal of Organizational Behavior 37(3): 309-325. 
Bruning PF and Campion MA (2017) A role-resource approach-avoidance model of job crafting: A multi-method integration and extension of job crafting theory. Academy of Management Journal, doi: 10.5465/amj.2015.0604.

Call ML, Nyberg AJ and Thatcher SM (2015) Stargazing: An integrative conceptual review, theoretical reconciliation, and extension for star employee research. Journal of Applied Psychology 100(3): 623-640.

Chan SC (2014) Paternalistic leadership and employee voice: Does information sharing matter?. Human Relations, 67, 667-693.Crandall CS, Silvia PJ, N'Gbala AN, Tsang JA and Dawson K (2007) Balance theory, unit relations, and attribution: The underlying integrity of Heiderian theory. Review of General Psychology 11(1): 12-30.

Demerouti E (2014) Design your own job through job crafting. European Psychologist 19237 247.

Demerouti E Bakker AB and Leiter M (2014) Burnout and job performance: The moderating role of selection, optimization, and compensation strategies Journal of Occupational Health Psychology 19 96-107.

Demerouti E Bakker AB and Halbesleben JRB (2015a) Productive and counterproductive job crafting: A daily diary study. Journal of Occupational Health Psychology 20: 457-469

Demerouti E, Bakker AB and Gevers J (2015b) Job crafting and extra-role behavior: The role of work engagement and flourishing. Journal of Vocational Behavior 91: 87-96.

Demerouti E and Peeters MCW (2017) Transmission of reduction-oriented crafting among colleagues: A diary study on the moderating role of working conditions. Journal of Occupational and Organizational Psychology. doi:10.1111/joop.12196

Duan J Li C Xu Y and Wu C (2017) Transformational leadership and employee voice behavior: A Pygmalion mechanism. Journal of Organizational Behaviour 38: 650-670.

Edwards JR and Lambert LS (2007) Methods for integrating moderation and mediation: A general analytical framework using moderated path analysis. Psychological Methods 12(1): $1-22$.

Ellis PD (2010) The Essential Guide to Effect Sizes: An Introduction to Statistical Power, MetaAnalysis and the Interpretation of Research Results. Cambridge, UK: Cambridge University Press.

Ferris GR, Treadway DC, Perrewe PL, Brouer RL, Douglas C and Lux S (2007) Political skill in organizations. Journal of Management 33(3): 290-320.

Gagné M and Deci EL (2005) Self-determination theory and work motivation. Journal of Organizational Behavior 26(4): 331-362. 
Gevers J and Demerouti E (2013) How supervisors' reminders relate to subordinates' absorption and creativity. Journal of Managerial Psychology 28(6): 677-698.

Gilboa S, Shirom A, Fried Y and Cooper C (2008) A meta-analysis of work demand stressors and job performance: Examining main and moderating effects. Personnel Psychology 61(2): 227-271.

Goldberg LS and Grandey AA (2007) Display rules versus display autonomy: Emotion regulation, emotional exhaustion, and task performance in a call center simulation. Journal of Occupational Health Psychology 12(3): 301-318.

Grant AM (2007) Relational job design and the motivation to make a prosocial difference. Academy of Management Review 32(2): 393-417.

Grant AM (2008) Does intrinsic motivation fuel the prosocial fire? Motivational synergy in predicting persistence, performance, and productivity. Journal of Applied Psychology 93(1): 48-58.

Grant AM and Ashford SJ (2008) The dynamics of proactivity at work. Research in Organizational Behavior 28: 3-34.

Grant AM and Berg J (2011) Prosocial motivation at work: When, why, and how making a difference makes a difference. In: Cameron K and Spreitzer G (eds) Oxford Handbook of Positive Organizational Scholarship. Oxford, UK: Oxford University Press, 28-44.

Grant AM and Berry J (2011) The necessity of others is the mother of invention: Intrinsic and prosocial motivations, perspective-taking, and creativity. Academy of Management Journal 54(1): 73-96.

Grant AM and Bolino M (2016) The bright side of being prosocial at work, and the dark side, too: A review and agenda for research on other-oriented motives, behavior, and impact in organizations. Academy of Management Annals, 10: 599-670.

Grant AM and Mayer DM (2009) Good soldiers and good actors: Prosocial and impression management motives as interactive predictors of affiliative citizenship behaviors. Journal of Applied Psychology 94(4): 900-912.

Grant AM and Parker SK (2009) Redesigning work design theories: The rise of relational and proactive perspectives. Academy of Management Annals 3(1): 317-375.

Grant AM and Bolino M (2016) The bright side of being prosocial at work, and the dark side, too: A review and agenda for research on other-oriented motives, behavior, and impact in organizations. Academy of Management Annals 10 599-670. 
Griffin MA Neal A and Parker SK (2007) A new model of work role performance: Positive behavior in uncertain and interdependent contexts. Academy of Management Journal 50: $327-347$.

Halbesleben JRB (2010) A meta-analysis of work engagement: Relationships with burnout, demands, resources, and consequences. In: Bakker AB and Leiter MP (eds) Work Engagement: A Handbook of Essential Theory and Research. New York, NY: Psychology Press, 102-117.

Hochschild A (1983) The Managed Heart: Commercialization of Human Feeling. Berkeley, CA: University of California Press.

Hu L-T and Bentler PM (1999) Cutoff criteria for fit indices in covariance structure analysis: Conventional criteria versus new alternatives. Structural Equation Modeling 6(1): 155.

Kabasakal H and Bodur M (2002) Arabic cluster: A bridge between east and west. Journal of World Business 37(1): 40-54.

Latham GP and Pinder CC (2005) Work motivation theory and research at the dawn of the twenty-first century. Annual Review of Psychology 56: 495-516.

Laurence GA (2010) Workaholism and expansion and contraction oriented job crafting: The moderating effects of individual and contextual factors. Unpublished doctoral dissertation, Syracuse University, Syracuse, NY.

Laurence GA, Fried Y and Yan W (2010) Are salarymen drones or active shapers of their jobs? Workaholism and expansion and contraction oriented job crafting in Japan and China. Paper presented at Asia Academy of Management 2010 Conference, Macau, China.

LePine JA and Van Dyne L (1998) Predicting voice behavior in work groups. Journal of Applied Psychology 83(6): 853-868.

Long DM Baer MD Colquitt JA Outlaw R and Dhensa-Kahlon RK (2014) What will the boss think? The impression management implications of supportive relationships with star and project peers. Personnel Psychology 68(3): 463-498.

Lu C Wang H Lu J Du D and Bakker AB (2014) Does work engagement increase person-job fit? The role of job crafting and job insecurity. Journal of Vocational Behavior 84(2): $142-152$.

Luthans F and Youssef CM (2007) Emerging positive organizational behavior. Journal of Management 33(3): 321-349.

Maas CJ and Hox JJ (2004). Robustness issues in multilevel regression analysis. Statistica Neerlandica 58: 127-137. 
MacKinnon DP and Fairchild AJ (2009) Current directions in mediation analyses. Current Directions in Psychological Science 18(1): 16-20.

Madrid HP Patterson MG Birdi KS Leiva PI and Kausel EE (2014) The role of weekly highactivated positive mood, context, and personality in innovative work behavior: A multilevel and interactional model. Journal of Organizational Behavior 35(2): 234256.

Marinova S Peng A Lorinkova N Van Dyne L and Chiaburu D (2015) Change-oriented citizenship: A meta-analysis of individual and job design predictors. Journal of Vocational Behavior 88: 104-120.

Maxwell SE Kelley K and Rausch JR (2008) Sample size planning for statistical power and accuracy in parameter estimation. Annual Review of Psychology 59: 537-563.

Morgeson FP and Campion MA (2003) Work design. In: Borman W, Klimoski R and Ilgen D (eds) Handbook of Psychology, Volume 12: Industrial and Organizational Psychology. New York, NY: John Wiley, 423-452.

Muller D, Judd CM and Yzerbyt VY (2005) When moderation is mediated and mediation is moderated. Journal of Personality and Social Psychology 89(6): 852-863.

Niessen C Weseler D and Kostova P (2016) When and why do individuals craft their jobs? The role of individual motivation and work characteristics for job crafting. Human Relations 69(6): 1287-1313.

Ng TWH and Feldman DC (2012) Employee voice behavior: A meta-analytical test of the conservation of resources framework. Journal of Organizational Behavior 33: 216-234.

Ng TWH and Feldman DC (2013) Changes in perceived supervisor embeddedness: Effects on employees' embeddedness, organizational trust, and voice behavior. Personnel Psychology 66: 645-685.

Ng TWH and Feldman DC (2015). Idiosyncratic deals and voice behavior. Journal of Management 41(3): 893-928.

Ohly S Sonnentag S Niessen C and Zapf D (2010) Diary studies in organizational research: An introduction and some practical recommendations. Journal of Personnel Psychology 9: 79-93.

Parker SK, Bindl UK and Strauss K (2010) Making things happen: A model of proactive motivation. Journal of Management 36(4): 827-856.

Penner LA, Dovidio JF, Piliavin JA and Schroeder DA (2005) Prosocial behavior: Multilevel perspectives. Annual Review of Psychology 56: 365-392. 
Petrou P and Bakker AB (2016) Crafting one's leisure time in response to high job strain. Human Relations 69(2): 507-529.

Petrou P, Bakker AB and Van den Heuvel M (2017) Weekly job crafting and leisure crafting: Implications for meaning-making and work engagement. Journal of Occupational and Organizational Psychology 90(2): 129-152.

Petrou P, Demerouti E, Peeters MCW, Schaufeli W and Hetland J (2012) Crafting a job on a daily basis: Contextual correlates and the link to work engagement. Journal of Organizational Behavior 33(8): 1120-1141.

Petrou P, and Demerouti E (2015). Trait-level and week-level regulatory focus as a motivation to craft a job. Career Development International, 20; 102-118.

Prieto A (1992) A method for translation of instruments to other languages. Adult Education Quarterly 43(1): 1-14.

Rasbash J, Browne W, Healy M, Cameron B and Charlton C (2000) MLwiN (Version 2.1): Interactive Software for Multilevel Analysis. London, UK: Multilevel Models Project, Institute of Education, University of London.

Raub S and Robert C (2010) Differential effects of empowering leadership on in-role and extrarole employee behaviors: Exploring the role of psychological empowerment and power values. Human Relations, 63: 1743-1770.

Rich BL, Lepine JA and Crawford ER (2010) Job engagement: Antecedents and effects on job performance. Academy of Management Journal 53(3): 617-635.

Rioux SM and Penner LA (2001) The causes of organizational citizenship behavior: A motivational analysis. Journal of Applied Psychology 86(6): 1306-1314.

Rudolph CW, Katz IM, Lavigne KN and Zacher H (2017) Job crafting: A meta-analysis of relationships with individual differences, job characteristics, and work outcomes. Journal of Vocational Behavior 102: 112-138.

Schaufeli WB and Bakker AB (2004) Job demands, job resources, and their relationship with burnout and engagement: A multi-sample study. Journal of Organizational Behavior 25(3): 293-315.

Schaufeli WB, Bakker AB and Salanova M (2006) The measurement of work engagement with a brief questionnaire: A cross-national study. Educational and Psychological Measurement 66(4): 701-716.

Scherbaum CA and Ferreter JM (2009) Estimating statistical power and required sample sizes for organizational research using multilevel modeling. Organizational Research Methods 12(2): 347-367. 
Selig JP and Preacher KJ (2008) Monte Carlo method for assessing mediation: An interactive tool for creating confidence intervals for indirect effects [Computer software]. Available from http://quantpsy.org/.

Sheldon KM and Houser-Marko L (2001) Self-concordance, goal attainment and the pursuit of happiness: Can there be an upward spiral? Journal of Personality and Social Psychology 80(1): 152-165.

Tims M, Bakker AB and Derks D (2013) The impact of job crafting on job demands, job resources, and well-being. Journal of Occupational Health Psychology 18(2): 230-240.

To ML, Fisher CD, Ashkanasy NM and Rowe PA (2012) Within-person relationships between mood and creativity. Journal of Applied Psychology 97(3): 599-612.

Van den Broeck A, Vansteenkiste M, De Witte H and Lens W (2008) Explaining the relationships between job characteristics, burnout and engagement: The role of basic psychological need satisfaction. Work \& Stress 22(3): 277-294.

Van Woerkom M Oerlemans W and Bakker AB (2016) Strengths use and work engagement: A weekly diary study. European Journal of Work and Organizational Psychology 25(3): 384-397.

Van Wingerden J Bakker AB and Derks D (2017) Fostering employee well-being via a job crafting intervention. Journal of Vocational Behavior 100(1): 164-174.

Van Wingerden J Derks D and Bakker AB (2017) The impact of personal resources and job crafting interventions on work engagement and performance. Human Resources Management 56: 51-67.

Wang HJ, Demerouti E and Bakker AB (2016) A review of job crafting research: The role of leader behaviors in cultivating successful job crafters. In: Parker SK and Bindl UK (eds) Proactivity at Work. London, UK: Routledge, Ch.4.

Wrzesniewski A and Dutton JE (2001) Crafting a job: Revisioning employees as active crafters of their work. Academy of Management Review 26(2): 179-201.

Xanthopoulou D, Bakker AB and, Ilies R (2012) Everyday working life: Explaining withinperson fluctuations in employee well-being. Human Relations 65(9): 1051-1069. 
Table 1. Means, standard deviations, reliabilities and inter-correlations between the model variables.

\begin{tabular}{|c|c|c|c|c|c|c|c|c|c|c|c|c|}
\hline & Variables & $\begin{array}{l}\text { Within-person variance } \\
(\%)\end{array}$ & Mean & SD & 1 & 2 & 3 & 4 & 5 & 6 & 7 & 8 \\
\hline 1 & $\begin{array}{l}\text { Week } \\
\text { Week Level }\end{array}$ & n.a. & 4.00 & 2.00 & n.a. & & & & & & & \\
\hline 2 & Expansion oriented RJC & $35 \%$ & 3.90 & .73 & $.34 * *$ & $(.85)$ & & & & & & \\
\hline 3 & Contraction oriented RJC & $37 \%$ & 2.07 & .99 & -.02 & -.04 & $(.93)$ & & & & & \\
\hline 4 & Work engagement & $30 \%$ & 3.71 & .61 & $.28 * *$ & $.34 * *$ & $-.16^{* *}$ & $(.87)$ & & & & \\
\hline 5 & Work performance & $39 \%$ & 3.72 & .81 & $.21 * *$ & $.21 * *$ & $-.21 * *$ & $.32 * *$ & $(.78)$ & & & \\
\hline 6 & $\begin{array}{l}\text { Voice } \\
\text { General Level }\end{array}$ & $38 \%$ & 3.71 & .72 & $.33^{* *}$ & $.33^{* *}$ & .03 & $.41 * *$ & $.14^{*}$ & $(.81)$ & & \\
\hline 7 & Prosocial motives & n.a. & 3.57 & .98 & n.a. & -.01 & -.04 & -.02 & .02 & -.02 & $(.92)$ & \\
\hline 8 & Impression management motives & n.a. & 3.43 & 1.00 & n.a. & .03 & .07 & -.05 & -.10 & -.02 & $-.17 * *$ & ( \\
\hline
\end{tabular}

Notes. Reliabilities are along the diagonal in parentheses.

Notes. $\mathrm{N}=301$ occasions ( 7 weeks nested in 43 employees).

For all week-level variables, we have used aggregate scores of the seven weeks; therefore, for all week-level variables, we have assigned participants a mean score of their seven measurements.

$* \mathrm{p}<.05 ; * * \mathrm{p}<.01 ; * * * \mathrm{p}<.001$. 
Table 2. Multilevel models for predicting employee work engagement, performance and voice for expansion oriented RJC

\begin{tabular}{|c|c|c|c|c|c|c|c|c|c|}
\hline \multirow[b]{3}{*}{ Variables } & \multirow{2}{*}{\multicolumn{2}{|c|}{$\begin{array}{c}\text { Dependent Variable: } \\
\text { Work Engagement } \\
\text { Model } 2\end{array}$}} & \multirow[b]{3}{*}{$\mathbf{t}$} & \multirow{2}{*}{\multicolumn{2}{|c|}{$\begin{array}{c}\text { Dependent Variable: } \\
\text { Work Performance } \\
\text { Model } 2\end{array}$}} & \multirow[b]{3}{*}{$\mathbf{t}$} & \multirow{2}{*}{\multicolumn{2}{|c|}{$\begin{array}{c}\text { Dependent Variable: } \\
\text { Voice } \\
\text { Model } 2\end{array}$}} & \multirow[b]{3}{*}{$\mathbf{t}$} \\
\hline & & & & & & & & & \\
\hline & Estimates & SE & & Estimates & SE & & Estimates & SE & \\
\hline Intercept & 3.71 & 0.05 & $74.2 * * *$ & 3.73 & 0.71 & $5.25 * * *$ & 3.71 & 0.06 & $61.83 * * *$ \\
\hline Week & 0.05 & 0.01 & $5.00 * * *$ & 0.05 & 0.02 & $2.50 * *$ & 0.07 & 0.01 & \\
\hline Lag of work engagement & 0.16 & 0.05 & $3.20 * *$ & & & & & & \\
\hline Expansion oriented RJC & 0.21 & 0.05 & $4.20 * * *$ & 0.02 & 0.06 & 0.33 & 0.16 & 0.05 & $3.20 * *$ \\
\hline Work engagement & & & & 0.28 & 0.08 & $3.50 * *$ & 0.27 & 0.06 & $4.50 * * *$ \\
\hline Lag of work performance & & & & 0.15 & 0.05 & $3.00 * *$ & & & \\
\hline Lag of voice & & & & & & & 0.15 & 0.04 & $3.75^{* * *}$ \\
\hline Level 1 intercept variance (SE) & 0.07 & 0.02 & & 0.27 & 0.07 & & 0.12 & 0.06 & \\
\hline Level 2 intercept variance (SE) & 0.22 & 0.02 & & 0.34 & 0.03 & & 0.23 & 0.02 & \\
\hline
\end{tabular}

Notes. $\mathrm{N}=301$ occasions ( 7 weeks nested in 43 employees). For all values, gamma coefficients, their corresponding standard error and t values are reported.

The indirect effect is calculated using an online interactive tool that generates an R score (http://quantpsy.org/medmc/medmc.htm). The first path of the indirect relationship relates to the association between expansion oriented RJC and work engagement $(0.21 ; 0.05)$, and the second path of the indirect relationship relates to the association between work engagement and work performance $(0.28 ; 0.08)$ and voice $(0.27 ; 0.06)$ when expansion oriented RJC is present in the equation. $* \mathrm{p}<0.05 ; * * \mathrm{p}<0.01 ; * * * \mathrm{p}<$ 0.001 
Table 3. Multilevel models for predicting employee work engagement, performance and voice for contraction oriented RJC

\begin{tabular}{|c|c|c|c|c|c|c|c|c|c|}
\hline \multirow[b]{3}{*}{ Variables } & \multirow{2}{*}{\multicolumn{3}{|c|}{$\begin{array}{c}\text { Dependent Variable: } \\
\text { Work Engagement } \\
\text { Model } 2 \\
\end{array}$}} & \multirow{2}{*}{\multicolumn{3}{|c|}{$\begin{array}{c}\text { Dependent Variable: } \\
\text { Work Performance } \\
\text { Model } 2 \\
\end{array}$}} & \multirow{2}{*}{\multicolumn{3}{|c|}{$\begin{array}{c}\text { Dependent Variable: } \\
\text { Voice } \\
\text { Model } 2\end{array}$}} \\
\hline & & & & & & & & & \\
\hline & Estimates & SE & $\mathrm{t}$ & Estimates & SE & $\mathrm{t}$ & Estimates & SE & $\mathrm{t}$ \\
\hline Intercept & 3.71 & 0.05 & $74.20 * * *$ & 3.73 & 0.71 & $5.25 * * *$ & 3.71 & 0.06 & $61.83 * * *$ \\
\hline Week & 0.08 & 0.01 & $8.00 * * *$ & 0.05 & 0.01 & $5.00 * * *$ & 0.09 & 0.01 & $9.00 * * *$ \\
\hline Lag of work engagement & 0.16 & 0.05 & $3.20 * *$ & & & & & & \\
\hline Contraction oriented RJC & -0.08 & 0.03 & $-2.67 * *$ & -0.11 & 0.04 & -0.33 & -0.05 & 0.03 & -1.66 \\
\hline Work engagement & & & & 0.26 & 0.07 & $3.71 * * *$ & 0.33 & 0.06 & $5.50 * * *$ \\
\hline Lag of work performance & & & & 0.15 & 0.05 & $3.00 * *$ & & & \\
\hline Lag of voice & & & & & & & 0.17 & 0.05 & $3.40 * * *$ \\
\hline Level 1 intercept variance (SE) & 0.08 & 0.02 & & 0.16 & 0.05 & & 0.11 & 0.06 & \\
\hline Level 2 intercept variance (SE) & 0.22 & 0.02 & & 0.35 & 0.03 & & 0.24 & 0.02 & \\
\hline
\end{tabular}

Notes. For all values, gamma coefficients, their corresponding standard error and t values are reported.

The indirect effect is calculated using an online interactive tool that generates an R score (http://quantpsy.org/medmc/medmc.htm). The first path of the indirect relationship relates to the association between contraction oriented RJC and work engagement $(-0.08 ; 0.03)$, and the second path of the indirect relationship relates to the association between work engagement and work performance $(0.26 ; 0.07)$ as well as voice $(0.33 ; 0.06)$ when contraction oriented RJC is present in the equation. $\mathrm{N}=301$ occasions $(7$ weeks nested in 43 employees).

$* \mathrm{p}<0.05 ; * \mathrm{p}<0.01 ; * * * \mathrm{p}<0.001$. 
Table 4. Multilevel models for the interaction between weekly relational job crafting (expansion and contraction oriented) and trait motives (prosocial and impression management motives) on weekly work engagement.

\begin{tabular}{|c|c|c|c|c|c|c|c|c|c|c|c|c|}
\hline \multirow[b]{3}{*}{ Variables } & \multicolumn{12}{|c|}{ Dependent Variable: Work engagement } \\
\hline & Model 1 & & & Model 2 & & & Model 3 & & & Model 4 & & \\
\hline & Estimates & SE & $\mathbf{t}$ & Estimates & SE & $\mathbf{t}$ & Estimates & SE & $\mathbf{t}$ & Estimates & SE & $\mathbf{t}$ \\
\hline Intercept & 3.71 & 0.06 & $61.83 * * *$ & 3.72 & 0.05 & $74.40 * * *$ & 3.72 & 0.05 & $74.40 * * *$ & 3.71 & 0.05 & $74.20 * * *$ \\
\hline Week & 0.05 & 0.01 & $5.00 * * *$ & 0.07 & 0.01 & $7.00 * * *$ & 0.05 & 0.01 & $5.00 * * *$ & 0.08 & 0.01 & $8.000 * * *$ \\
\hline Lag of work engagement & 0.15 & 0.05 & $3.00 * *$ & 0.16 & 0.05 & $3.20 * *$ & 0.14 & 0.05 & $2.80 * *$ & 0.18 & 0.05 & $3.60 * * *$ \\
\hline Expansion oriented RJC & 0.22 & 0.05 & $4.40 * * *$ & 0.016 & & & 0.22 & 0.05 & $4.40 * * *$ & & & \\
\hline Contraction oriented RJC & & & & -0.08 & 0.03 & $-2.66 * *$ & & & & -0.09 & 0.03 & $-3.00 * *$ \\
\hline Trait prosocial motives & 0.01 & 0.05 & 0.20 & 0.01 & 0.05 & 0.20 & & & & & & \\
\hline $\begin{array}{l}\text { Trait impression management } \\
\text { motives }\end{array}$ & & & & & & & 0.01 & 0.05 & 0.20 & 0.01 & 0.04 & 0.25 \\
\hline $\begin{array}{l}\text { Expansion oriented RCJ* } \\
\text { Prosocial motives }\end{array}$ & 0.07 & 0.04 & 1.75 & & & & & & & & & \\
\hline $\begin{array}{l}\text { Contraction oriented RCJ* } \\
\text { Prosocial motives }\end{array}$ & & & & 0.04 & 0.03 & 1.33 & & & & & & \\
\hline $\begin{array}{l}\text { Expansion oriented } \mathrm{RCJ} * \\
\text { Impression management } \\
\text { motives }\end{array}$ & & & & & & & -0.11 & 0.04 & $-2.75 * *$ & & & \\
\hline $\begin{array}{l}\text { Contraction oriented } \mathrm{RCJ} * \\
\text { Impression management } \\
\text { motives }\end{array}$ & & & & & & & & & & 0.07 & 0.04 & 1.75 \\
\hline $\begin{array}{l}\text { Level } 1 \text { intercept variance } \\
\text { (SE) }\end{array}$ & 0.07 & 0.02 & & 0.08 & 0.02 & & 0.11 & 0.02 & & 0.07 & 0.02 & \\
\hline $\begin{array}{l}\text { Level } 2 \text { intercept variance } \\
\text { (SE) }\end{array}$ & 0.21 & 0.01 & & 0.22 & 0.01 & & 0.21 & 0.02 & & 0.22 & 0.02 & \\
\hline
\end{tabular}

Notes. $a$ Statistical comparison with an intercept-only model at level 1 (not shown in the table). $\mathrm{N}=301$ occasions ( 7 weeks nested in 43 employees). For all values, gamma coefficients, their corresponding standard error and t values are reported. $* \mathrm{p}<0.05 ; * * \mathrm{p}<0.01 ; * * * \mathrm{p}<0.001$. 
Figure 1. Proposed model.

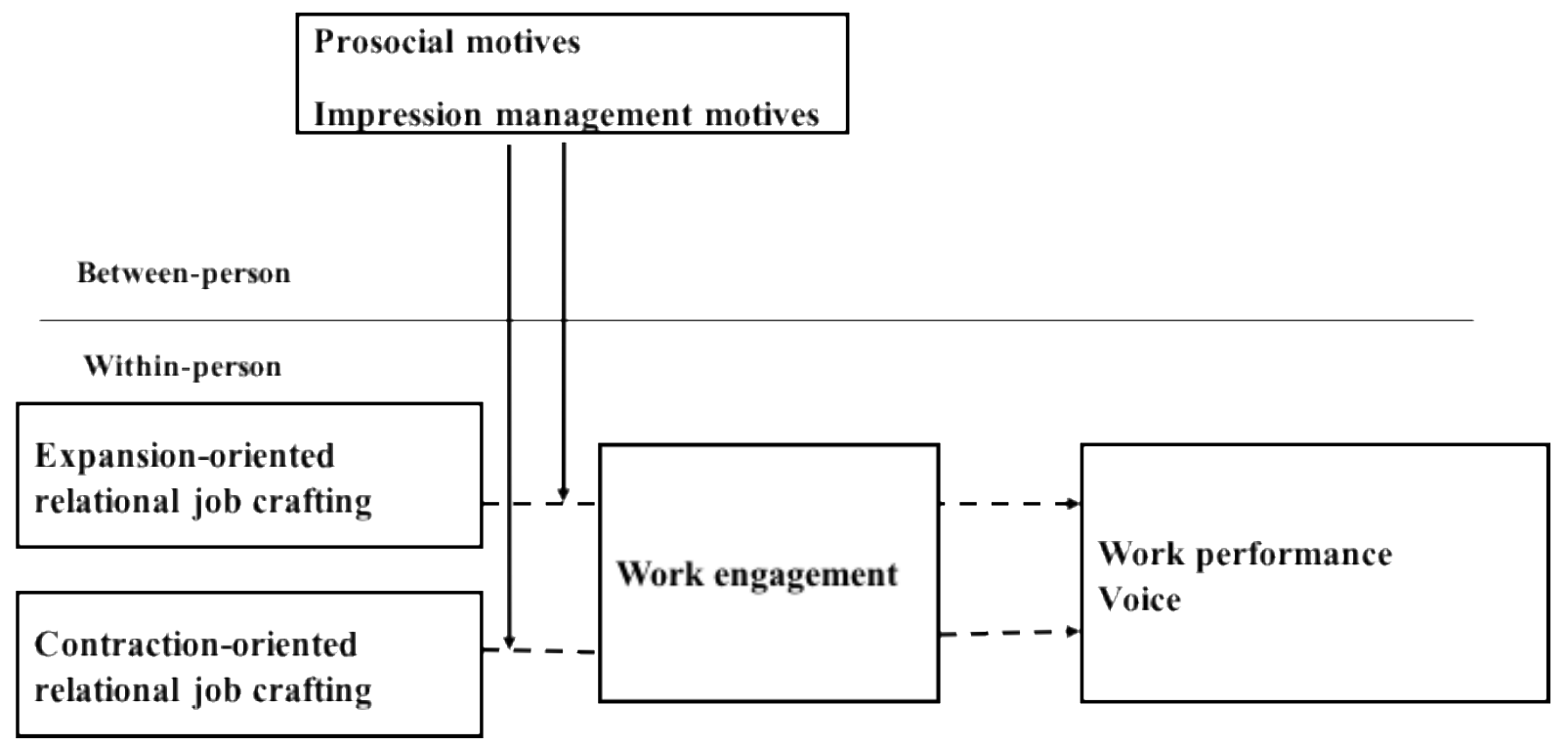

Figure 2. Interaction effect of impression management motives and expansion oriented relational job crafting on work engagement.

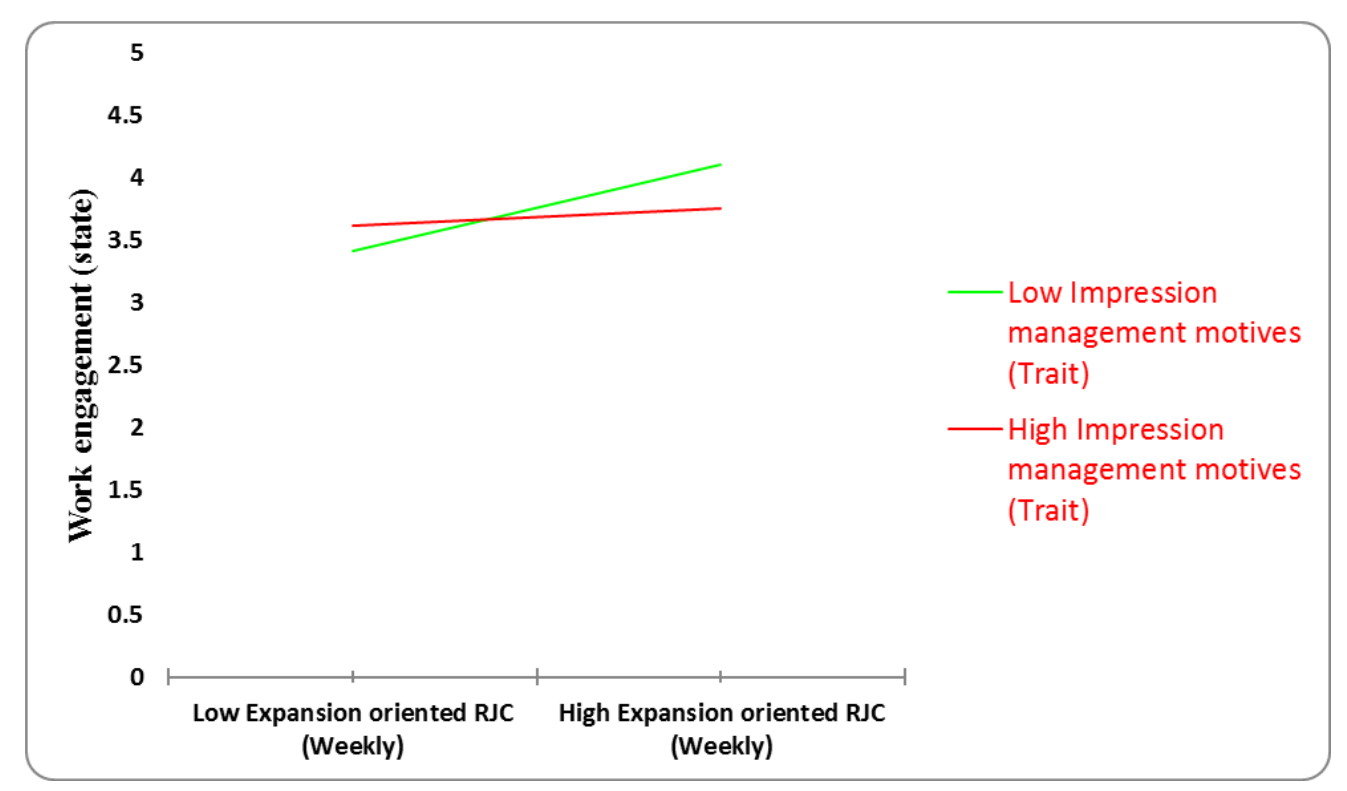

